\title{
CONHECIMENTOS PROFISSIONAIS MOBILIZADOS POR PROFESSORES ENGENHEIROS PARA GERIR DILEMAS DA PRÁTICA PEDAGÓGICA
}

Jefferson da Silva Moreira ${ }^{1}$

Marinalva Lopes Ribeiro ${ }^{1}$

\section{RESUMO}

O texto apresenta resultados de pesquisa qualitativa que objetivou investigar quais são os conhecimentos profissionais mobilizados por professores universitários de cursos de Engenharia de uma universidade pública, para gerir dilemas da sala de aula. Contribuições de Bardin, Juarrero, Legendre, Nono, Mizukami e Shulman, dentre outros, deram sustentação teórica à análise dos dados coletados por meio de um questionário que continha um caso de ensino seguido de questões, que foram analisadas por quatro docentes de Engenharia da Computação, Engenharia de Alimentos e Engenharia Civil. Os resultados evidenciam, como dilema dos professores, o fato de nem sempre se prepararem adequadamente para as aulas e de terem de lidar com as questões éticas da profissão e com o plágio em sala de aula. No que tange aos conhecimentos profissionais, os professores enfatizaram os conhecimentos do conteúdo específico, os pedagógicos do conteúdo e os didáticos, além daqueles relacionados à dimensão afetiva. Como fontes de conhecimentos, destacaram o estágio em docência e a aprendizagem com os pares.

Palavras-chave: Docência universitária. Dilemas profissionais. Formação de professores. Casos de ensino.

\footnotetext{
${ }^{1}$ Universidade Estadual de Feira de Santana, Feira de Santana, BA, Brasil.
} 


\title{
PROFESSIONAL KNOWLEDGE MOBILIZED BY TEACHER ENGINEERS IN ORDER TO MANAGE PEDAGOGICAL PRACTICE DILEMMAS
}

Jefferson da Silva Moreira

Marinalva Lopes Ribeiro

\begin{abstract}
This work presents the results of a qualitative research, which aimed to investigate professional knowledge mobilized by university teachers of engineering courses from a public university, in order to manage classroom dilemmas. Contributions from Bardin, Juarrero, Legendre, Nono, Mizukami, Shulman, among others, gave the theoretical background support to the data analysis. The data were collected through a questionnaire containing a teaching case, and through some questions answered by four teachers working on Computer Engineering, Food Engineering, and Civil Engineering courses. The results bring evidences that some of teacher's dilemmas are related to the fact that sometimes they are not properly prepared to their classes, to dealing with professional ethical issues, and classroom plagiarism. While talking about professional knowledge, teachers emphasize the specific content, pedagogy, and didactics, besides the affective dimension. As source of knowledge, they point out the teaching internship, and partnership learning.
\end{abstract}

Keywords: University teaching. Professional dilemma. Teacher training. Teaching cases. 


\section{INTRODUÇÃO}

Considerando-se que grande parte dos professores da educação superior não tem uma formação inicial para a docência, a tendência atual é de tratar a formação desses sujeitos no espaço institucional como desenvolvimento profissional. Para Marcelo García (1999), desenvolvimento profissional é o conjunto de processos e estratégias que facilitam a reflexão dos professores sobre a própria prática, contribuindo para gerar conhecimento prático e estratégico, capacitando-os a aprender com a experiência que vivem.

Assim, desde os anos 1980, Lee Shulman² ressaltou a necessidade de propiciar o desenvolvimento profissional dos professores a partir de casos de ensino, a fim de diminuir o abismo existente entre teoria e prática e ajudar ingressantes na carreira docente a pensarem com os professores mais experientes (NONO, 2005).

O método de casos é conhecido como uma pedagogia ativa, fundada sobre a análise de situações da empresa, que consiste em fazer estudar e discutir, de maneira argumentada, por um grupo de aprendizes, situações-dilema concretas, a partir de informações fornecidas pelos atores da empresa estudada. Tais informações dão lugar à escrita, por um professor experiente no domínio abordado, de um suporte de formação específico: o caso, ainda chamado de estudo de caso (JUARRERO, 2008).

Tal método foi aplicado, inicialmente, em diversas áreas antes da educação. Desde o final do século XIX, o método de caso foi formalizado por Langdell ${ }^{3}$ (1826-1906) na Escola de Direito da Universidade de Harvard, onde ele sistematizou a prática na formação de juristas. Em 1908, Eliot ${ }^{4}$ tomou a decisão de aplicá-lo sistematicamente para a formação dos futuros diplomados em Administração, em Harvard.

\footnotetext{
${ }^{2}$ Autor norte americano, atualmente presidente da Carnegie Foundation for the Advancement of Teaching (Fundação Carnegie para o Avanço do Ensino), onde tem produzido pesquisas na área de Educação com vistas a contribuir para a melhoria do processo de ensino e aprendizagem.

${ }^{3}$ Christopher Columbus Langdell é considerado o criador do método de casos, que passou a ser utilizado como ferramenta pedagógica na formação de advogados.

${ }^{4}$ Eliot foi um acadêmico americano selecionado como presidente de Harvard em 1869 . Teve um importante papel na transformação da universidade americana, principalmente no que concerne à pesquisa. Eliot serviu até o ano de 1909, tendo o mais longo prazo como presidente na história da universidade.
} 
Os casos de ensino são instâncias que revelam circunstâncias das práticas dos professores, oferecendo-lhes oportunidade para refletirem sobre situações cotidianas conflituosas. Enquanto na visão de Legendre (1998, p. 398, tradução nossa) “um caso é uma representação de uma situação real complexa que comporta certo número de dados (ou fatos) relatados que constituem materiais a serem objeto de análises variadas", para Shulman (1996), os casos são o retrato de situações reais ou fictícias da prática pedagógica que proporcionam oportunidades para que os docentes conheçam e deliberem reflexivamente, após o exame das consequências da ação, quer dizer, é uma forma de aprender sobre a própria experiência, relembrando, recontando, revivendo.

Quanto à estrutura, os casos evidenciam uma narrativa que ocorre em um tempo e em um local específicos; possuem começo, meio e fim; demonstram emoções, angústias, frustrações e alegrias vividas pelos protagonistas; retratam situações práticas da sala de aula - a forma de um professor ensinar um determinado conteúdo e as dificuldades que encontra nesse processo. Explanam, ainda, múltiplas situações-problema vividas pelos professores e as formas deles de agirem em determinada situação; e se fundamentam em análises teóricas, o que permite aos docentes mobilizarem os conhecimentos acadêmicos para fundamentarem as tomadas de decisões (NONO; MIZUKAMI, 2002).

O método comporta três fases: a primeira, uma análise individual pelo formando, a fim de diagnosticar a situação, a partir de um roteiro; a segunda, uma discussão em pequenos grupos, para confrontar os diagnósticos, formular e ordenar os problemas a resolver e construir uma solução; e a terceira, finalmente, uma discussão pelo plenário para confrontar as teses apresentadas e discutir as vantagens e inconveniências das soluções propostas pelos pequenos grupos (VAN STAPPEN, 1989).

Destacamos a inexistência de uma obrigatoriedade na legislação educacional brasileira sobre a especificidade de formação pedagógica para os docentes atuarem na educação superior. A Lei de Diretrizes e Bases da Educação Nacional - LDBEN (BRASIL, 1996), por exemplo, prescreve, no art. 66, que "a preparação para o exercício do magistério superior far-se-á em nível de pósgraduação, prioritariamente em programas de mestrado e doutorado".

Evidenciamos que circula nos meios acadêmicos um habitus institucionalizado que tende a desconsiderar a necessidade da formação pedagógica para o exercício da docência, tendo em vista que a lógica de que "quem sabe fazer, consequentemente, sabe ensinar" 
mantém-se intacta nos processos de seleção e ingresso na educação superior. No caso dos professores engenheiros, muitos são egressos de cursos de pós-graduação stricto sensu, com aprofundamento nos conhecimentos específicos dos diversos campos disciplinares e na pesquisa, todavia, desconhecendo questões atinentes aos processos de aprendizagem do adulto, com quem lidam cotidianamente na prática pedagógica.

Este artigo apresenta resultados finais de pesquisa que objetivou investigar os conhecimentos profissionais mobilizados por professores universitários que atuam em cursos de Engenharia Civil, Engenharia da Computação e Engenharia de Alimentos de uma universidade pública baiana, para gerir dilemas do cotidiano da prática pedagógica.

No que concerne aos aspectos metodológicos, esta investigação é de abordagem qualitativa, pois buscou compreender as subjetividades dos sujeitos colaboradores e o contexto complexo da realidade social em que estão inseridos, escutando as próprias vozes sobre os dilemas enfrentados nas práticas pedagógicas. Sabendo o quanto os docentes têm estado solitários, consideramos o fato de escutá-los, de provocá-los a refletir sobre o métier que assumiram, como uma oportunidade formativa por excelência.

O locus desta pesquisa foram três cursos: Engenharia Civil, Engenharia da Computação e Engenharia de Alimentos, tomando como sujeitos quatro professores universitários com formação inicial em cursos de bacharelado em Engenharia que lecionam nos referidos cursos. As idades deles variam entre 33 e 43 anos, três são do sexo feminino e um, do sexo masculino. Todos possuem a titulação de mestres e/ou doutores, com uma experiência profissional que varia entre quatro e dezessete anos. Destacamos que os nomes: Priscila, Luísa, Angélica e Ricardo são fictícios, usados para preservar as identidades desses indivíduos e primarmos pelos aspectos éticos da pesquisa.

Optamos por apresentar aos professores o caso de ensino "O dilema de Ricardo" de um roteiro de questões que orientou a análise da situação. Enviamos o questionário via endereço eletrônico para 50 professores. Todavia, obtivemos, apenas, quatro respostas. A

\footnotetext{
${ }^{5}$ Trata-se de um caso de ensino elaborado por Torres (2002), no qual são relatadas as itinerâncias e experiências profissionais de um professor formado em Engenharia Naval, que se aproximou da docência na universidade, inicialmente, por conta da pesquisa. No referido caso de ensino, o professor relata as experiências e tensões vividas durante o exercício da docência no ensino superior.
} 
seguir, analisamos os dados produzidos, para o qual nos aproximamos da técnica Análise de Conteúdo (BARDIN, 1977).

\section{CONHECIMENTOS PROFISSIONAIS MOBILIZADOS POR PROFESSORES UNIVERSITÁRIOS}

Apresentamos, nesta seção, o cotejamento dos dados produzidos por meio da aplicação do caso de ensino "O dilema de Ricardo", com o referencial teórico e epistemológico adotado em nosso estudo. O material foi organizado em três dimensões: a) Dilemas de professores universitários; b) Conhecimentos profissionais de professores universitários; c) Fontes de aquisição dos conhecimentos profissionais da docência. As três serão apresentadas a seguir.

\section{Dilemas profissionais de professores universitários}

Ao analisarem o caso de ensino "O dilema de Ricardo" (MUSSI, 2007), os professores participantes da pesquisa foram estimulados a relatar dilemas profissionais que vivenciaram no cotidiano da sala de aula universitária, além dos conhecimentos profissionais que foram mobilizados no cotidiano da prática pedagógica para gerir tais situações.

O termo dilema é aqui concebido na perspectiva de Zabalza (2004, p. 61): “[...] todo um conjunto de situações bipolares ou multipolares que se apresenta ao professor no desenrolar da sua atividade profissional [...]". Derivado do latim dilemma, o termo significa: "[...] situação embaraçosa com duas situações difíceis ou penosas"(HOLANDA, 1999, p. 682). Pelo fato de os dilemas dependerem dos conhecimentos, experiências e valores anteriores de cada professor, cada um é mais sensível para um determinado dilema que outro. Sendo assim, um dilema apresentado por uma professora colaboradora desta pesquisa está relacionado à profissionalização docente:

[...] pelo fato de turmas anteriores não terem um senso crítico, curiosidade, interesse de entender tudo, eu transmiti a aula abordando alguns pontos de maneira um tanto superficial. Outras vezes, por conta da sobrecarga de trabalho, não consegui pesquisar e preparar a aula tão bem. E aí, os alunos começaram a querer entender melhor certos conceitos/informações passadas e eu não consegui responder. Porém, prometi esclarecer na aula seguinte. Estudei e pesquisei bastante $e$ tirei as dúvidas. Apesar de certo constrangimento e frustração que passei por não conseguir responder ao questionamento dos alunos, essas experiências serviram para eu aprender mais e contribuir para a 
aprendizagem dos alunos e aprimorar as próximas aulas para a turma e para as turmas seguintes (PRISCILA) ${ }^{6}$.

O fato de a professora Priscila pensar que se os estudantes não tinham senso crítico, curiosidade nem interesse poderia ser um motivo para ela não levar a docência a sério, quer dizer, fazer a aula de qualquer forma, sem estudar, sem se preparar adequadamente para o exercício da profissão, o que seria um equívoco. Todavia, segundo ela própria declara, "os alunos começaram a querer entender melhor certos conceitos/informações passadas, mas ela não conseguiu responder". Foi necessário passar por um constrangimento para a docente dar-se conta da necessidade de domínio do conhecimento específico da disciplina sob responsabilidade dela, o que, para Shulman (1986), é um aspecto central da vida da sala de aula.

O caso de ensino pode ter dado à Priscila a oportunidade de refletir sobre a própria profissão e possibilitar a mudança de representações iniciais de que a docência é um métier simples, que franqueia o estudo e a pesquisa constante. A reflexão pode ter trazido um impacto sobre a identidade profissional de tal professora.

Outro dilema apresentado, como resultado desta pesquisa, foi a questão ética, especificamente o plágio. De fato, os atores universitários parecem desconhecer que se trata de uma questão a ser discutida na academia, tendo em vista a necessidade da formação moral dos profissionais que estão sendo graduados. Afinal, vivem, no Brasil, com uma crise moral sem precedentes. Qual seria, então, o papel dos professores na transformação dessa realidade? Rios (2006) nos ajuda a responder quando aborda o papel político-moral do educador. Se o motor da ação do professor deve ser a necessidade concretamente presente no contexto socioeconômico em que se vive, cabe a tal profissional atendê-la ou até mesmo não atendê-la. Depende do ato compromissado e livre do docente. Vejamos o relato da professora sobre o plágio:

No semestre 2010.2, ao corrigir o primeiro relatório da turma, percebi que dos 5 relatórios corrigidos 4 eram iguais [...] O que diferenciava um relatório do outro era a quantidade de parágrafos, que eles juntavam para parecer maiores ou davam um enter para separar. Sem contar com algumas palavras que eles tiveram o trabalho de trocar: contudo, no entanto, ainda assim, todavia, porém (LUISAA).

\footnotetext{
${ }^{6}$ Os depoimentos foram coletados por meio de questionário digital. Os nomes dos sujeitos são fictícios.
} 
Na redação, não ficou clara a ação da professora para lidar com tal dilema. Será que ela puniu os estudantes? Ou aproveitou a oportunidade para a formação ética desses sujeitos? Será que estava consciente dos deveres que possui de formar eticamente os licenciandos? Ou acreditava, como muitos, que o seu papel seria apenas o de "transmitir" os conteúdos específicos do componente curricular?

Ficou evidenciado, na escrita da docente Angélica, que as cópias da internet trazem, como dilema, a dificuldade de os estudantes interpretarem de maneira reflexiva:

\begin{abstract}
Já notei o desinteresse dos estudantes com atividades repetidas e já testadas. Após alguns planejamentos mais criativos para aulas práticas ou trabalhos em grupo, e os estudantes responderam com cópias da Internet, que não conseguiam interpretar de maneira reflexiva. Tive algumas boas respostas, mas pontuais. Também já tive muitas dificuldades com os técnicos laboratoristas, que encaram tudo como excesso de tarefa, e realizam minimamente ou de maneira incompleta (ANGÉLICA).
\end{abstract}

Diante do exposto, recorremos a Sanz de Acedo Lizárraga (2010) para refletirmos sobre competências cognitivas superiores a serem desenvolvidas pelos graduandos. Quando a professora Angélica fala sobre as dificuldades dos estudantes em "interpretar de maneira reflexiva", é preciso deixar claro que, para interpretar a informação, é necessário desenvolver o pensamento compreensivo, que requer as habilidades de comparar, classificar, analisar, sintetizar, sequenciar, averiguar razões e extrair conclusões. Vale destacar, então, que todas essas habilidades, para serem avaliadas, têm que fazer parte do planejamento e da intervenção de cada docente. Contudo, deixamos um questionamento: o professor que atua na educação superior tem tido oportunidade de desenvolver-se profissionalmente para o exercício da docência?

\title{
Conhecimentos profissionais de professores universitários
}

O postulado teórico construído por Shulman, knowledge base ("base de conhecimento"), pode ser definido como um conjunto de conhecimentos, habilidades, compreensões e disposições que um professor necessita para desenvolver as atividades profissionais em qualquer nível e modalidade de ensino, possibilitando que a efetivação da aprendizagem dos alunos aconteça (MIZUKAMI, 2004). Esse conjunto de conhecimentos da docência é desenvolvido constantemente, antes mesmo do período da formação inicial dos professores, e prolonga-se 
por toda a carreira profissional, principalmente nas relações que esses estabelecem com os alunos no contexto da sala de aula.

Na perspectiva de Mizukami (2004), os elementos que constituem essa base de conhecimentos são de natureza diversa, porém são indispensáveis para a atuação profissional docente. Tais conhecimentos se desenvolvem profundamente a partir das experiências profissionais e da reflexão sobre a prática pedagógica, desde que sejam fundamentados teoricamente e objetivados.

Os aspectos anteriormente mencionados nos levam a tensionar a cultura historicamente estabelecida nos meios acadêmicos, que tende a considerar necessário que os professores dominem, somente, o conteúdo específico das disciplinas que ministram. Conforme ressaltam Soares e Cunha (2010), a pós-graduação stricto sensu, locus de formação do professor universitário, está voltada desde as origens, no Brasil, para a formação do pesquisador, o que nos parece uma negligência com a docência na educação superior e as singularidades dessa área.

Nesse aspecto, colocamos em tela a declaração de Priscila, que sinaliza, como conhecimento profissional imprescindível para o exercício da docência universitária, o domínio do conteúdo específico e a capacidade de relacionar esse conhecimento com o exercício da profissão:

Ter o conhecimento dos conteúdos relacionados às disciplinas que ministra. Além disso, associá-los com a profissão e com outras disciplinas do curso, saber apontar onde os estudantes aplicarão aqueles conhecimentos quando no exercício da profissão (PRISCILA).

No trecho anterior, a professora considera relevante, dentre os conhecimentos profissionais da docência, estabelecer a relação entre a teoria e a prática, ou seja, o que se aprende na universidade com os conhecimentos necessários ao exercício da profissão. Com efeito, Legendre (1998) avalia que muitos estudantes desconsideram a pertinência da formação, quando essa não estabelece a relação entre os saberes teóricos e os saberes práticos. Desse modo, acontece uma hierarquização dos modos de saber, sendo o saber prático mais valorizado do que o saber teórico, o que representa um obstáculo para o formador.

Artaud (1981, 1989 apud LEGENDRE, 1998) faz distinção entre o saber teórico e o saber da experiência. Enquanto o saber teórico consiste num saber mais formalizado e sistematizado, frequentemente institucionalizado, cuja aquisição repousa essencialmente sobre a transmissão 
cultural e educativa, o saber da experiência é mais intuitivo e pessoal e é possuído pelo aprendiz sobre um determinado objeto antes de ter sido submetido a um conjunto de conhecimentos teóricos sobre tal objeto. A aquisição desse conhecimento depende da autoaprendizagem.

Tal distinção evidencia o problema dos conhecimentos inertes, que podem conduzir à simples transmissão de saberes teóricos, sem se levar em conta os conhecimentos prévios elaborados pelo aprendiz. Por conta disso, acontece uma competição entre os saberes formais e os saberes intuitivos, e não uma real coordenação entre eles, de modo que os saberes formais são mobilizados apenas no contexto universitário.

O distanciamento entre teoria e prática se revela, também, por meio da oposição frequentemente estabelecida entre ação e reflexão. Se esta é considerada importante para orientar e sustentar a ação, o excesso de reflexão pode frear a ação ou a propensão a agir poderá inibir a reflexão. Não se trata, pois, de negar as diferenças, buscando dissolver uma das formas de saber na outra. Mas torna-se necessário buscar ultrapassar a dicotomia entre teoria e prática, promovendo uma interação mais dialética dessas formas de saber, articulando o saber teórico com as questões trazidas pela prática.

Priscila salienta, ainda, a necessidade de que os professores universitários saibam expor o conteúdo de maneira clara, valendo-se de imagens, vídeos e outros recursos didáticos e metodológicos que possam colaborar para manter os estudantes interessados nas aulas:

Saber expor o conteúdo de maneira clara, numa sequência lógica, didática, utilizando recursos (imagens, vídeos, esquemas etc.) como forma de facilitar o entendimento do que está sendo passado e manter o estudante atento e interessado na aula. E analisar a melhor maneira de avaliar o aluno acerca da assimilação do que foi transmitido (PRISCILA).

Ao analisarmos esse excerto à luz do referencial teórico, podemos perceber que Priscila se refere, basicamente, a um dos elementos que constituem a base de conhecimentos profissionais para o ensino, denominado por Shulman (2014) como conhecimento pedagógico do conteúdo, que é de autoria do professor, construído cotidianamente durante as aulas, a partir do contato estabelecido com os estudantes, sendo, portanto, constantemente melhorado e modificado ao longo da carreira profissional. Assim, o conhecimento pedagógico do conteúdo pode ser evidenciado pela tentativa dos professores de explicarem as próprias ideias, valendo-se de analogias, metáforas, simulações, representações visuais e modelos, 
para garantir a apropriação dos conteúdos pelos estudantes (NONO; MIZUKAMI, 2002; NONO, 2011; MIZUKAMI et al., 2010).

O desenvolvimento do conhecimento pedagógico do conteúdo implica a compreensão sobre o porquê de ensinar um tópico de uma disciplina específica, além dos princípios e técnicas necessárias para o ensino. Trata-se de um conhecimento apreendido, majoritariamente, no campo de atuação profissional, no qual o docente ocupa um papel de autoria, e que é amalgamado por outros conhecimentos profissionais da docência, construídos tanto na formação inicial quanto na continuada. Esse tipo de conhecimento oferece aos professores orientações sobre como ensinar uma determinada matéria, observar as dificuldades dos alunos na aprendizagem, as capacidades desses para se apropriarem de um conceito particular, as concepções prévias comuns que possuem, além dos materiais curriculares que "são organizados na disciplina e como tópicos particulares são melhor incluídos no currículo" (MIZUKAMI, 2004, p. 8).

Outro aspecto destacado por Priscila é a importância da experiência profissional no campo da Engenharia:

A experiência profissional (conhecimento mais prático) em campo também é importante. Sinto certa dificuldade em algumas disciplinas por não estar atuando como Engenheira no mercado de trabalho, o que dificulta expor aos alunos o que é ou não prática na indústria (PRISCILA).

Sem sombras de dúvidas, o conhecimento da experiência, o saber tácito, adquirido no exercício da profissão, possui relevância para os formadores de profissionais desenvolverem um trabalho que atenda às especificidades que o cotidiano exige. Outro elemento sinalizado por dois dos sujeitos da nossa pesquisa como conhecimentos profissionais indispensáveis para o exercício da docência universitária é a capacidade de o professor lançar mão de planejamento e estratégias didáticas de acordo com o objetivo que pretende alcançar, além de favorecer atividades que primem pelo desenvolvimento da autonomia dos estudantes:

[...] o professor precisa conhecer e lançar mão de diferentes abordagens didáticas, pois, muitas vezes, o problema vem do excesso de dirigismo que os professores usam para procurar cumprir o programa de um componente curricular. Sair do dirigismo implica em construir percursos não tão controlados, o que é bom, mas também gera dúvidas nos próprios professores sobre suas habilidades de gerenciar novas situações (RICARDO). 
Planejamento didático diferenciado para os objetivos que ele pretende atingir: se é autonomia, reflexão, correlação, raciocínio, memorização, etc. pois muitas vezes eu tenho vontade de fazer diferente, mas não sei exatamente como, e a tentativa equivocada causa desgaste com os estudantes, que percebem essa fragilidade (ANGÉLICA).

O depoimento de Ricardo está em consonância com as contribuições teóricas de Shulman, ao destacar os processos de raciocínio pedagógico que são mobilizados pelo professor ao transformar o conhecimento específico das disciplinas em ensino. Mizukami et al. (2010, p. 6) nos advertem para o fato de que o raciocínio pedagógico "consiste em técnica de raciocínio e ação, abrangendo seis aspectos comuns ao ato de ensinar: compreensão, transformação, instrução, avaliação, reflexão e nova compreensão". Destacam, ainda, que é por meio desse processo que os conhecimentos profissionais da docência são construídos.

A professora Angélica sinaliza a importância do desenvolvimento de planejamentos visando ao alcance dos objetivos, embora reconheça a necessidade formativa para planejar situações de ensino que possibilitem a aprendizagem dos estudantes.

De fato, o planejamento da prática pedagógica possui um papel vital nos mais diversos níveis e modalidades de ensino. Para Abreu e Masetto (1990), o planejamento possui um papel fundante na concretização de estratégias que visem desenvolver capacidades cognitivas superiores nos estudantes.

No que se refere à avaliação da aprendizagem, o professor Ricardo considera as formas processual e somativa, devendo o docente oferecer feedbacks aos estudantes, possibilitandoIhes a regulação da aprendizagem:

É importante saber planejar e realizar avaliações, tanto somativas como processuais/formativas. É preciso dialogar, interagir e negociar com os estudantes, receber e oferecer feedback, o que exige o desenvolvimento de habilidades processuais normalmente desprezadas num ambiente técnico como a área de engenharia. É importante, obviamente, que o professor tenha o conhecimento técnico necessário para ensinar o que se propõe. É bastante útil ter um referencial teórico de como funciona o processo de aprendizagem realizado pelo aprendiz, para que as situações de ensino-aprendizagem propostas sejam mais eficazes. E, por fim, é preciso saber tratar em sala de aula questões éticas importantes à profissão de engenharia e ao fazer acadêmico, de maneira apropriada ao contexto que os estudantes estão vivendo (RICARDO). 
É importante destacar, conforme salienta Almeida (2011), que as práticas de avaliação da aprendizagem estão em consonância com uma base teórica e epistemológica que as orienta. Assim, é indispensável que o professor que atua na educação superior tenha um profundo domínio do conhecimento que Shulman (2014) denomina de "pedagógico geral". Esse conhecimento ultrapassa o domínio dos conhecimentos relativos às diversas áreas específicas e está relacionado aos modos de aprendizagem dos alunos; aos seus processos de desenvolvimento humano e cognitivo; a como eles aprendem; ao conhecimento dos contextos educacionais - aspectos relacionados ao cotidiano da sala de aula, à forma de se relacionar com os estudantes e de manejar as classes. Inclui, também, conhecimentos sobre aspectos da gestão escolar e sobre os contextos macro, como de comunidades e/ou culturas; conhecimento das questões curriculares e da política de conhecimento que é desenvolvida pelas instituições educacionais e de "programas e materiais destinados ao ensino de tópicos específicos e da matéria em diferentes níveis e conhecimento de fins, metas e propósitos educacionais e de seus fundamentos filosóficos e históricos" (MIZUKAMI, 2004, p. 5).

Por fim, mas não menos importante, destacamos as colocações de Ricardo sobre a necessidade de um conhecimento para tratar das questões éticas que envolvem a profissão de Engenharia e o fazer acadêmico, aspectos que já foram discutidos anteriormente, mas que nos convocam a dialogar com Freire (1996, p. 16) quando destaca que o ensino exige, de modo sine qua non, uma dimensão ética para o seu exercício: "não é possível pensar os seres humanos longe, sequer, da ética, quanto mais fora dela. Estar longe ou pior, fora da ética, entre nós, mulheres e homens, é uma transgressão".

\section{Fontes de aquisição de conhecimentos profissionais de professores universitários}

Os sujeitos colaboradores da pesquisa explicitaram que os conhecimentos profissionais que possuem acerca da docência foram sendo construídos em diversos contextos e espaços, dentre os quais, ressaltam a contribuição do estágio de docência, realizado durante o período do mestrado, conforme pode ser observado no excerto a seguir:

No Mestrado, fiz o estágio-docência, em que aprendi bastante. $O$ professor da disciplina em que fiz esse estágio já ensina há muito tempo na UEFS, é um professor excelente e me ajudou no preparo das aulas, como utilizar o espaço do quadro, como lidar com a insegurança (PRISCILA). 
Pelo visto, o estágio em docência mostra-se fundamental instrumento para a formação e o exercício da docência. Todavia, como constataram Freitas e Ribeiro (2014), tal componente curricular não tem sido priorizado por muitos programas de pós-graduação, em que se torna obrigatório apenas para estudantes que não tenham experiência comprovada na docência do ensino superior.

$\mathrm{Na}$ experiência da professora Priscila, o estágio mostrou-se uma fonte de aquisição de conhecimentos profissionais, o que vai ao encontro do estudo de Freitas (2016) que mostra a importância do estágio para ajudar o formando, principalmente, na resolução de conflitos da prática pedagógica.

Chamou-nos a atenção o fato de a colaboradora da pesquisa referir-se ao professor da disciplina do estágio como fonte de conhecimentos da docência. De fato, a interação entre o professor experiente e o estagiário, como também constatou Freitas (2016), possibilita a observação da prática e a incorporação das orientações na construção da identidade profissional docente.

Nessa mesma linha de raciocínio, os dados evidenciam que a troca de experiência com colegas da profissão, sendo ou não parentes, pode se constituir uma fonte de aquisição de conhecimentos profissionais, como revela, ainda, Priscila:

Além disso, minha mãe e minha irmã também são professoras e, muitas vezes, me deram/dão conselhos em algumas situações em que sinto dificuldade na condução das mesmas. Troca de experiência com colegas de profissão também ajudaram/ajudam (PRISCILA).

Tais colegas mais experientes, com habilidades de regência, comunicação, com conhecimento do conteúdo e algumas qualidades pessoais, como iniciativa, flexibilidade, paciência e sensibilidade, cuja tarefa é assessorar didática e pessoalmente ao professor principiante, como acontece na experiência da professora Priscila, funcionam como mentores (VAILLANT; MARCELO GARCÍA, 2012). Eles ajudam substancialmente na formação do professor iniciante, até que este torne-se experto, isto é, não necessite mais de um modelo formal para adotar uma resposta adequada a determinada situação ou conflito. 


\section{CONSIDERAÇÕES FINAIS}

A representação que os professores têm sobre a docência, construída no grupo social onde vivem, desde a infância e nas escolas por onde passaram na condição de alunos, faz com que tenham o sentimento de já saberem ensinar, quando iniciam o métier na educação superior, mesmo sem formação específica para tal profissão. Como afirma Legendre (1998), eles julgam, por consequência, que a formação pedagógica não acrescenta grande coisa aos conhecimentos anteriores que possuem. E, como mostram os dados, muitos fazem a aula de qualquer forma, sem se prepararem adequadamente para o exercício da profissão, o que se constitui um dilema ao serem questionados pelos estudantes quando não sabem dar a resposta adequada.

Outro dilema apresentado pelos docentes está relacionado à ética e à formação moral dos futuros profissionais. Ora, tendo-se em vista que o plágio constitui-se dilema da prática docente, toda a comunidade universitária precisa refletir sobre tal realidade, que não é local, mas demanda enfrentamento de forma propositiva e corajosa.

A questão do plágio ou da cópia pela internet ainda nos faz pensar sobre o papel do professor na orientação dos estudantes para a produção do texto científico. A quem cabe tal formação? $\mathrm{O}$ que a universidade tem feito com os estudantes que adentram essa instituição mediante políticas públicas de inclusão, mas que necessitam desenvolver uma série de habilidades complexas, como as de comparar, classificar, analisar, sintetizar, sequenciar, averiguar razões e extrair conclusões?

No que tange aos conhecimentos profissionais, os professores universitários destacaram o conhecimento específico das disciplinas ministradas, a efetivação da relação entre a teoria e a prática, o conhecimento da didática para expor os conteúdos de forma clara e sair do dirigismo, a avaliação das aprendizagens dos estudantes, a experiência profissional na área da Engenharia, a inovação educacional, a fim de construir aulas diferentes, e, por fim, os conhecimentos relativos à dimensão afetiva para saberem dialogar, interagir e negociar com os estudantes.

Com relação às fontes de conhecimentos dos professores universitários, esta pesquisa evidenciou o estágio em docência e os colegas mais experientes, tomados como uma espécie 
de mentores, cuja função tem sido a de assessorar didática e profissionalmente o professor iniciante na profissão.

Não podemos negar que o método de caso comporta alguns limites. Embora faça relação com a realidade, o caso não equivale à realidade do ensino, que se torna cada vez mais complexa, motivo pelo qual não se deve subestimar as dificuldades potenciais relacionadas ao uso dessa estratégia na formação de professores.

Todavia, o método de caso propiciou aos sujeitos desta pesquisa a possibilidade de refletirem sobre as práticas que desenvolvem, mesmo que de forma esporádica, constituindo-se, além de instrumento de pesquisa, um momento de desenvolvimento profissional dos colaboradores, o que nos instiga a divulgá-lo e a utilizá-lo em processos de formação de professores da educação superior.

\section{REFERÊNCIAS}

ABREU, M. C.; MASETTO, M. T. O professor universitário em aula. 8. ed. São Paulo: Autores Associados, 1990.

ALMEIDA, L. R. M. Avaliação da aprendizagem: reflexões sobre os desafios atuais. In: RIBEIRO, M.; MARTINS, E.; CRUZ, A. (Orgs.). Docência no ensino superior: desafios da prática educativa. Salvador: EDUFBA, 2011.

BARDIN, L. Análise de conteúdo. Lisboa: Edições 70, 1977.

BRASIL. Lei de Diretrizes e Bases da Educação Nacional. Lei no 9.394, de 20 de dezembro de 1996. Brasília, DF, 1996.

FREIRE, P. Pedagogia da autonomia: saberes necessários à prática educativa. São Paulo: Paz e Terra, 1996.

FREITAS, E. N. O estágio docência na formação de professores da educação superior: representações de estudantes do mestrado em Saúde Coletiva. 2016. 138 f. Dissertação (Mestrado em Educação) - Universidade Estadual de Feira de Santana, Feira de Santana, 2016.

FREITAS, E. N.; RIBEIRO, M. L. O estágio docência e a formação de professores da educação superior. In: Anais do XXII Encontro de Pesquisa Educacional do Norte e Nordeste, Universidade Federal do Rio Grande do Norte, Natal, 2014. 
JUARRERO, J. M. Petite histoire de la méthode des cas. Paris: CCMP Chambre de Commerce et d'industrie de Paris, out. 2008.

LEGENDRE, Marie-Françoise. Pratique reflexive et études de cas: quelques enjeux à l'utilisation de la méthode des cas en formation des maîtres. Revue des sciences de l'éducation, v. XXIV, n. 2, 1998.

MARCELO GARCÍA, C. Formação de professores: para uma mudança educativa. Porto, Portugal: Porto Editora, 1999.

MIZUKAMI, M. G. Aprendizagem da docência: algumas contribuições teóricas de Lee Shulman. Revista Centro de Educação UFSM, v. 29, n. 2, 2004.

MIZUKAMI, M. G. et. al. Escola e aprendizagem da docência: processos de investigação e formação. São Carlos: EDUFSCar, 2010.

MUSSI, A. Docência no ensino superior: conhecimentos profissionais e processos de desenvolvimento profissional. 2007. 294 f. Tese (Doutorado em Educação) - Pontifícia Universidade Católica de São Paulo, São Paulo, 2007.

NONO, M. A. Casos de ensino e professoras iniciantes. 2005. $238 \mathrm{f}$. Tese (Doutorado em Educação), Universidade Federal de São Carlos, São Carlos, 2005.

NONO, M. A. Professores iniciantes: o papel da escola em sua formação. Porto Alegre: Mediação, 2011.

NONO, M. A.; MIZUKAMI, M. G. Casos de ensino e processos de aprendizagem profissional docente. Rev. Bras. Estud. Pedagog., Brasília, v. 83, n. 203/204/205, p. 72-84, jan./dez. 2002.

RIOS, Terezinha Azerêdo. Ética e competência. São Paulo: Cortez, 2006.

SANZ DE ACEDO LIZÁRRAGA, Maria Luisa. Competencias cognitivas en educación superior. Madrid: Narcea Ediciones, 2010.

SHULMAN, L. S. Conhecimento e ensino: fundamentos para a nova reforma. Cadernos Cenpec. São Paulo, v. 4, n. 2, p. 196-229, dez. 2014.

SHULMAN, L. S. Just in case: reflections on learning from experience. In: COLBERT, J.; TRIMBLE, K.; DESBERG, P. (Eds.). The case for education. Contemporary approaches for using case methods. Needham Height: Allyn Bacon, 1996, p. 197-217. 
SHULMAN, L. S. Those who understand: knowledge growth in teaching. Educational Researcher, v. 15, n. 2, 1986, p. 4-14.

SOARES, S. R.; CUNHA, M. I. Formação do professor: a docência universitária em busca de legitimidade. Salvador: EDUFBA, 2010.

TORRES, S. R. A formação de docentes da engenharia e processos de mudanças: contribuições para a formação de professores. 2002. 225 f. Tese (Doutorado em Educação) - Pontifícia Universidade Católica de São Paulo, São Paulo, 2002.

VAILLANT, D.; MARCELO GARCÍA, Carlos. Ensinando a ensinar. As quatro etapas de uma aprendizagem. Curitiba: UTFPR, 2012.

VAN STAPPEN, Y. La méthode des cas. Revue Pédagogie collégiale, v. 3, n. 2, 1989, p. 1618.

ZABALZA, M. Diários de aula: contributo para o estudo dos dilemas práticos dos professores. Portugal: Porto Editora, LDA, 2004.

\section{Jefferson da Silva Moreira}

Licenciado em Pedagogia pela Universidade Estadual de Feira de Santana (UEFS). Professor da educação básica. Atuou como bolsista de iniciação científica pela Fundação de Amparo à Pesquisa do Estado da Bahia (FAPESB) e pelo Conselho Nacional de Desenvolvimento Científico e Tecnológico (CNPq). É membro do Núcleo de Estudos e Pesquisas sobre Pedagogia Universitária (NEPPU).

moreirajefferson92@yahoo.com.br

\section{Marinalva Lopes Ribeiro}

Doutora em Educação pela Université de Sherbrooke (2004), com Mestrado em Educação pela Universidade Federal da Bahia. Possui graduação em licenciatura em Letras pela Universidade Estadual de Feira de Santana (1974) e em Pedagogia pela Federação das Escolas Superiores de Ilhéus e Itabuna (1976). Professora do Departamento de Educação da Universidade Estadual de Feira de Santana (UEFS). Coordenadora do Núcleo de Estudos e Pesquisas sobre Pedagogia Universitária (NEPPU).

marinalva_biodanza@hotmail.com 